\title{
LOS ESPACIOS DE LA REALIDAD DESEADA: EDUARDO Wilde ENTRE EL FUEGo DE PROMETEO Y EL YO BAJO

\author{
LA LLUVIA
}

\section{María de los Ángeles Martín Peón Universidad Complutense de Madrid}

Title: The spaces of desired reality: Eduarado Wilde between the fire of Prometheus and the self in the rain

\begin{abstract}
Through a series of compositions of the work published in 1899 Prometeo Cía, its author, Eduardo Wilde, will show us that the modern process that Argentine society experienced in the last decades of the 19th century, led to the triumph of a secularized, unimportant, earthly world, with a marked attachment to contingency and pragmatism, in which there seemed to be no space for the emergence of any activity belonging to the domains of irrationality, of spirituality, of Beauty and, consequently, of the poetic. Against that civilization that guaranteed progress of an exclusively material nature, Wilde proposed the ideal values of his Promethean civilization, and against the objective, functional ugliness of the world, the beauty of its subjectivity: to it and through an element, water, his texts will lead us.
\end{abstract}

Key words: Eduardo Wilde. Material and Spiritual Progress. Prometheus. Forms of water. Poetic Spaces.

Hacia el año 1899 y bajo el título de PrometeoECía ${ }^{1}$ saldrían publicadas una serie de composiciones correspondientes al escritor argentino vinculado a la llamada Generación del 80, Eduardo Wilde, en las que muchas veces a través de los sutiles pero poderosos filtros del humor, se nos ofrecía una visión de aquella cosmópolis en la que se había convertido Buenos Aires a raíz de su proceso de modernización: avalanchas inmigratorias, desarrollo industrial y tecnológico, orientación pragmática, agitación bancaria y mercantil, eran algunos de los factores de riesgo que hasta cierto punto supusieron el agotamiento, o más aun, impedimento, de la prosperidad humana tal y como la concebía Wilde. Desde su punto de vista, dicha prosperidad no debería de ser otra que la surgida a costa de un progreso de índole espiritual, algo que parecía distar bastante del que por entonces había echado raíces en la capital argentina.

${ }^{1}$ La acentuación y ortografía de los textos citados en el presente artículo se han ajustado a las normas actuales de la RAE. 
Para entender el porqué de esa incomodidad que el autor acusa con respecto a su realidad y estimar las consecuencias que tal situación adversa podría tener en el sujeto artístico, se verificarán, en primer lugar, las peculiaridades de las condiciones socioeconómicas y culturales relativas a la época. Con este fin, más allá de la información aportada por el propio Wilde, nos apoyaremos en dos tipos fundamentales de fuentes: por una parte, en las correspondientes a aquellos testimonios facilitados por alguno de los escritores contemporáneos a él, muchos de ellos compañeros de Generación (véase García Mérou: 1973), y por otra, en toda una serie de estudios críticos que confirmarán cómo ese ambiente de materialismo dominante efectivamente existente- sobre el cual se asentaba una burguesía filistea desprovista de gusto o sensibilidad, no fomentaba la emergencia, consolidación y recepción de cualquier actividad espiritual, estética e intelectiva ${ }^{2}$.

En segundo lugar, habremos de determinar cuál es (y qué significa) el diseño de esa realidad alternativa deseada por él. Para ello, teniendo en cuenta el estrecho vínculo establecido entre las dimensiones espacial y humana y, en especial, la capacidad proyectiva, identificativa y simbólica que estos ámbitos le suelen brindar al individuo ${ }^{3}$, se llevará a cabo una revisión de los textos pertenecientes a este PrometeoECía, con el propósito de registrar la diversidad de espacios poéticos -espacios, en un sentido amplio: físicos y

${ }^{2}$ En este sentido son ilustrativos los trabajos llevados a cabo por Malosetti (2003) (quien nos plantea el problema bajo la óptica de las artes plásticas) y Jitrik (1968). La ratificación de un entorno hostil a la creación literaria, a los productos del pensamiento, aparecerá asimismo recogida en los estudios realizados por Marún (1993), Ghiano (1953), Prieto (2006) y Viñas (1995), en los que además se va a exponer una continuidad, e incluso agravamiento, de este problema entre los futuros escritores adscritos al modernismo. De igual modo se nos presenta en Calinescu (1991) la difícil relación entre la individualidad artística y el grupo social en el seno de esa modernidad marcada por la secularización, la urbanización, los intereses materiales, la economía del dinero y la progresiva fuerza de la burguesía.

${ }^{3}$ Las publicaciones de Aínsa (2006) y Bachelard (1965) ratifican esta conexión espacialexistencial, la noción del que llamaríamos espacio vivido. La obra de Romero (1976) nos ofrece una visión de dicho nexo, exponiendo la trabazón existente entre los cambios sufridos por la ciudad latinoamericana a través del tiempo y los registrados en la ideología. 
meta-físicos - contenidos en su conjunto, para una posterior sistematización y clasificación de los mismos que nos permita reconocer los valores que estos representan. Unido al hecho de ser-uno con el espacio, a la intervención de la subjetividad desde o hacia lo externo, consideraremos igualmente la implicación y el alcance del que podríamos denominar yo lírico (Gullón: 1984), tan decisivo en ese acto de construir / crear una realidad personal, en la que la dimensión simbólica ${ }^{4}$ de sus elementos integrantes tendrá un papel decisivo.

Así pues, tal como adelantábamos al inicio, el modelo de crecimiento que triunfaba en la capital argentina, en aquel centro de expansión sobresaturado de bienes materiales, parecía ser más que representativo del tipo concreto de civilización del que renegaba nuestro autor, por considerarla "contrahecha” y aquella que rotunda y desafortunadamente "quita a todas las cosas de este mundo su encanto poético” Wilde (1914: 53), según él mismo nos confesaba en el que sería su proyecto autobiográfico Aguas abajo.

Estas condiciones sobre las que se asentaba la población bonaerense contemporánea a él, la de una urbe cuyo avance se actualizaba constantemente por las fuerzas generadoras y nada invisibles de un materialismo dominante, fueron causa de que se abriese una cierta quebradura entre sujetos que como Wilde, que como la mayoría de los integrantes de la referida Generación, pretendían un desarrollo ascendente del pensamiento, de lo intelectivo, de las potencias en general del alma humana. Esa serie de potencias resultaban visiblemente incompatibles con las determinantes de una sociedad que en aquel momento de crecimiento férreo, fundamentalmente imantado por lo pragmático, se reafirmaba desatenta a las riquezas del espíritu. De este modo, en mayor o en menor medida, el núcleo de intelectuales surgido en torno a dicha década se convertía en censor a conciencia de su

\footnotetext{
${ }^{4} \mathrm{~A}$ este respecto, la lectura de Bachelard (2002) nos da exhaustivas muestras de esa potencialidad que uno de los elementos omnipresente en este estudio de Wilde -el aguadesarrolla en la subjetivización de lo real, en la ensoñación, en lo poético.
} 
realidad más inmediata, pues, en el diseño de esta no había espacio ni tiempo para lo inmaterial; así, entre chanzas y dolorosos atisbos, se denuncia por ejemplo cómo en tales circunstancias "Los ferrocarriles y las fábricas manufactureras han reemplazado con ventaja a los idilios y a los sonetos" Wilde (1878: 33).

El nombre del personaje mítico al que su obra PrometeoECía antes mencionada hacía alusión, apuntaba asimismo al concepto que nuestro autor tenía sobre cuál debería ser la naturaleza de la civilización ideal, conveniente y propia de las aspiraciones del ser humano: la de la llamada "RAZA PROMETEAnA" Andrade (1887: 102). De ella y de sus características nos iba a dar noticia en las primeras páginas con las que se abría este volumen, precisamente al exponernos su valoración de aquel canto de Prometeo que Olegario V. Andrade, otra de las figuras adscritas a la Generación del 80, había compuesto.

Esta creación de Andrade retomaba el tema del titán, en concreto del que sería conocido como "EL TITAN INMORTAL DEL PENSAMIENTO" (1887: 96), quien tras robar a los dioses un fuego representativo de poderes de índole espiritual, de superioridad, de independencia, y entregárselo a los hombres dotándolos así de nuevas y de extraordinarias fuerzas, no podría sino recibir el correspondiente castigo divino, según se verifica en este caso, pero también en diferentes momentos de las letras argentinas:

[...] Prometeo es el mito más elevado e intelectual de la mitología y se desprende que el titán fue el generador del hombre, el creador de la esperanza, que dotó del fuego espiritual a los hombres; él es el numen de la mente, el civilizador e iniciador de las artes, el precursor, el pensador; él hizo al hombre eterno, induciéndole a renovarse. Méndez (1915: 27)

Además, las escasísimas expectativas que Eduardo Wilde mostraba ante el hecho de que, a mayores del asunto mitológico elegido por Andrade para su composición, esta pudiese llegar a ser entendida o aceptada por parte del público a causa de su intensidad poética, ayudarán a dejar al descubierto 
una diferencia de sensibilidades: la establecida entre quienes en estos tiempos cultivaban una literatura uncida a la subjetividad, al florecimiento del intelecto y a cierta incontinencia acusada en la búsqueda y cultivo de una Belleza con mayúscula (habitualmente desvinculada de valores determinados por lo que era útil o rentable), y aquella sociedad sin reposo o sin alma para percibirla. Así lo expresaría ya desde el inicio de dicho escrito:

Nosotros estamos muy ocupados y no tenemos tiempo para leer versos.

$[\ldots]$

Estamos ocupados de la Bolsa, de las cédulas hipotecarias, de las tarifas de avalúos, de la ley de papel sellado, y del banco nacional, que anuncia con gran pompa operaciones y no descuenta un pagaré de cinco pesos, firmado por Rothschild.

Y usted nos habla de Prometeo.

¿Quién era ese Prometeo?

¿Era algún agiotista?

¿Tenía acciones de las minas de Amambay y Maracayú?

¿O era exportador de frutos del país?

No, nada de esto era. No se ocupaba de ninguna de esas profesiones que hacen la ruina de algunas familias y la fortuna de uno que otro asiduo a la especulación.

¡Se ocupaba del libre pensamiento!. Wilde (1899: 3-4)

Podía decirse que el latido vertiginoso de aquel ámbito de vida encerrado bajo el caparazón urbano -caparazón industrial, fabril, febril, sin pausa- fuese también el de sus habitantes: el de su cuerpo, el de su sentir, el de su mente. Sus ritmos acaban haciéndose uno con el de esa metrópolis con la que tienden a acompasarse y en la que todo parece reducirse a un acto desnaturalizado, a un desfilar desenfrenado, tristemente coreográfico y caótico. En esta dinámica, los seres resultarán cosificados a la manera de un objeto nada más que cuantificable, cuya presencia se confirma y exhibe supeditada con frecuencia a la enumeración. Esa forma de existir, casi indiferenciada, no va más allá de aquella que los define como simples elementos constitutivos - y en ocasiones funcionales- de una entidad mayor, heterogénea; en 
el seno de esta, la dimensión humana y la complejidad que compete a cada individuo, personalmente, particularmente, esencialmente, desaparecen:

[...] cien apagadores, mil transeúntes, tres mil industriales, once mil viejas, todos los octogenarios, todos los panaderos, los proveedores de los mercados, los mozos, los viejos, las mujeres, los perros, los caballos, los lecheros saltando a compás, arrodillados sobre un edificio de tarros[...]; los repartidores de diarios y en fin, los vendedores de todo y los compradores de todo[...] salen, bajan, pululan, se atropellan, se empujan, hablan, gritan, llaman, golpean, produciendo un ruido hipócrita, que parece silencio y la algazara humana comienza a las barbas del sol[...]. Wilde (1899: 13-14).

A partir de tales premisas y siguiendo pautas y códigos recurrentes en diferentes composiciones de este PrometeoECía, nos encontramos con uno de los elementos que justamente representarán al yo poético frente a ese espacio despoetizado, hostil, propio de aquella ciudad modernizada tan poco prometeica que surge, y en cuya actividad no parece haber ocasión sino para el comercio y para lo ya apenas humano que las exigencias e imperativos económicos de este tráfago mercantil de entidades contantes y sonantes acabarán prácticamente neutralizando: dicho elemento es el agua y, en especial, la lluvia.

Esta última daría título a uno de los escritos pertenecientes a la referida obra, en el cual, de alguna forma Wilde no deja de abrir la veda a cierta identificación establecida entre dos llamémosles fenómenos: el de su subjetividad y el atmosférico. Esta clave-llave que propicia dicho agente meteorológico expondrá sus textos a las condiciones de una realidad desplegada, multiplicada y hasta cierto punto compleja.

Así, mediante esta manifestación específica de una naturaleza pronunciadamente acuática, lluviosa, a través de su presencia activa pero sobre todo activada por el autor, el entorno, el espacio, lo percibido, en gran parte se re-realizan o des-realizan con respecto a los niveles que por el contrario acostumbraban a considerarse dentro de lo habitual: aquellos marcados por lo evidente, por lo objetivo, por lo simplificado; en definitiva, por lo más 
normal, por ese orden cotidiano, usual y reglamentario, en el que, al igual que sucedía con la mayoría de la población retratada por dicho escritor población incapacitada o visiblemente apática ante determinadas "formas elevadas del arte y de la literatura” Malossetti (2003: 356)—, todo vivía ajeno a lo poético.

Podría decirse además que según el modo en cómo vaya a ser recibido este accidente atmosférico, se perfilarán en el texto dos actitudes diametralmente opuestas que a su vez devienen en representación de dos mundos enfrentados: el del artista y el del filisteo, el de lo espiritual y el de la materia.

Este par de reacciones respectivamente encarnadas por un sujeto lírico, que es Wilde (para quien la lluvia se presentará como un motivo de Belleza, decididamente inconmensurable), y en el otro extremo por aquel sujeto prosaico, urbano, el cual verá en su aparición una experiencia mensurable, solo tenida en cuenta según resulte útil y rentable - o no- por sus previsibles efectos sobre la Bolsa y el comercio (pues la cantidad de agua precipitada será medida por los pluviómetros y convertida en "dato estadístico y objeto de especulación” Wilde (1899: 34)), nos sitúan, como decíamos, ante el choque de dos tipos de civilización. Hablamos de la de Prometeo y la del agiotista (volviendo a hacer uso de los términos del propio autor) o, de lo que vendría resultando equivalente: la de lo ideal frente a la de lo real y la de los territorios del alma frente a los del cuerpo, por mencionar alguna de esas parejas que se reafirman antagónicas. A partir de esta diferenciación, la ciudad se definirá como un ámbito indudablemente hostil para quien en esa época intentase promover en ella, en lo que representa, cualquier actividad relacionada con las potencias del espíritu.

El recorrido por alguna de las composiciones que dan consistencia a esta obra, nos revelará una asimilación, no solo intuida sino incluso manifiesta, entre ese yo emisor que se involucra en la vivencia de lo poético y la lluvia. Así, hallaremos muestras desiguales de esa cierta ósmosis entre 
ambos, más o menos perfecta, más o menos consciente, más o menos voluntaria.

Estos grados diferentes de identificación recién mencionada funcionarán además como conectores con otros tantos niveles de la realidad (realidad intervenida, literaria), a los que Wilde y la lluvia nos conducirán a partes iguales y que sin embargo pasarán inadvertidos o serán simplemente desestimados por aquel hombre pragmático, apresurado y casi mecanizado, indiferente ante la Belleza, que se presentaba como el producto estrella de la civilización moderna. Una civilización, cuyo asentamiento señalaba a ese paradigma de ciudad, al que en ocasiones Wilde solía oponerse revalidando su inclinación por lo rural, por la naturaleza, tal y como por ejemplo expresaría en una de las piezas de este libro titulada Vida moderna. En ella, decide literalmente huir de la sociedad capitolina (la mal llamada civilizada), de sus redes esclerosantes y deshumanizadoras, para regenerarse en la salubre autenticidad del campo, en ese ámbito de encuentro con una parte esencial del ser humano, el cual, desprovisto de distracciones banales o de imposiciones convencionales de diversa índole, paradójicamente se convierte en un escenario capaz de favorecer el desarrollo de la actividad intelectiva:

Ocupo una casa vacía que tiene ocho habitaciones, un gran patio enladrillado y un fondo con árboles y con barro. Tengo dos caballos de montar y uno de tiro. Mi dotación de amigos es reducida; total: dos viejos maldicientes. He traído libros y paso mi vida leyendo, paseando, comiendo y durmiendo. Esto por sí solo constituye una buena parte de la felicidad; el complemento ¡quién lo creyera! se encuentra también a mi alcance, aquí, en este pueblo solitario y en esta casa medio arruinada y desierta.

Soy completamente feliz! Básteme decirte que nadie me invita a nada, que no hay banquetes, ni óperas, ni bailes[...] (1899: 101).

Los niveles antes señalados pertenecientes a esa realidad a la que podríamos denominar anormal, en tanto que adulterada -des-realizada, rerealizada- por un sujeto lírico que, como veremos, parecerá emerger al comprobarse poroso con la lluvia, se harán visibles a través de los siguientes 
espacios sellados por la textura y por los textos de este PrometeoECía. Estas esferas que el yo emisor construye desde la subjetividad, se nos ofrecerán como un desvío intencionado con respecto a las que por el contrario delimitan ese otro ámbito vital: el de la realidad común, el prosaico, el del comerciante, el del burgués ajetreado, el del hombre sin sensibilidad y grosero, hombre en busca de riquezas y moderno ciudadano resultante de una civilización cuyo progreso indeseable obedece a todo orden predominantemente material.

Eduardo Wilde y la lluvia (u otras formas asociadas a ella dentro de su sistema personal de representaciones, como pudieran serlo el agua, los accidentes hidrográficos, la humedad, las nubes...), ambos de espaldas a esa gran urbe que aniquila el espíritu y acaso la sustancia más intrínseca del hombre, nos abren paso a la siguiente multiplicidad de estratos sobre los que el autor, a costa de la realidad ordinaria (y en más de un aspecto, diríamos ramplona), edifica lo poético.

Lejos de proponer una división rígida, puesto que todos ellos se interrelacionan o contaminan entre sí, en su método lírico reconoceremos espacios, tanto físicos como conceptuales, cuyo carácter extraordinario apunta a una serie de vivencias fundamentalmente marcadas por el distanciamiento. En este caso, y de un modo un tanto genérico, podríamos hablar de los escenarios de la infancia (distanciamiento temporal, nostalgia de un estado de idealidad perdida), así como los de la propia psiquis (distanciamiento del exterior, experiencia de la introversión). Otros, sin embargo, parecen cimentarse en un suceso especialmente centrado en la transformación. De este surgirían aquellos que se construyen al ser intervenidos, adulterados, bien por una presencia activa del extrañamiento, bien por la disolutiva, corrosiva, del humor.

A continuación, y siguiendo esta clasificación espacial, nos referiremos a una serie de ejemplos que bajo la coincidencia anteriormente aludida entre la identidad acuática y la del yo emisor, nos introducen en esa bella 
dimensión subjetivamente codificada de una realidad improductiva, ajena a la funcionalidad y por lo tanto discordante con el diseño del mundo que el agiotista solía hacer a su medida.

Determinadas, como decíamos, por el distanciamiento, entre las posibilidades circunscritas a los espacios de la infancia hallamos en primer lugar aquella que a través de la civilización infantil nos presenta un modelo de entidad pura, vinculada a la naturaleza y a sus elementos, dotada para la conservación de una cierta irracionalidad, facultada para lo instintivo y también, por esta causa, habilitada para la comprensión de las esencias. Opuestos a estos patrones, se imponen sin embargo los de la cultura adulta. La contaminación de lo racional o el encorsetamiento de los hábitos son algunos de los factores que los definen y nos sugieren una consolidación de ese tipo de sociedad desvitalizada, en la que dicha aptitud cognitiva intuitiva, la que se corresponde con los primeros años de vida, se habrá perdido. Así afirma por ejemplo el autor: "Cuando quiera saber usted el valor de una cosa, pregúnteselo a los instintos. El sistema nervioso de un niño critica mejor que los autores clásicos" (4).

De acuerdo con esta distribución, con esta fórmula identificativa que en un solo concepto logrará ceñir al yo lírico con la realidad poética, la capacidad de asombro, los dominios de la infancia y, por supuesto, los del agua en sus múltiples formas de manifestación, son numerosas las muestras que se suceden para dar cauce a este tipo de civilización positiva, tan alejada de la que define a la urbe de comerciantes, experimentada, automatizada, atenta a lo material y decididamente elusiva ante las riquezas conmovedoras del espíritu: "su corazón como el de un pájaro, golpeaba la caja endeble de su pecho, $\mathrm{y}$ atraído por el abismo, por la tormenta, por las nubes, soltaba su imaginación de cinco años, a la orilla del río, donde sus oídos recogían los rugidos de las olas" (4-7); o también: 
La primera vez que recuerdo haber visto llover, fue durante la convalecencia de una grave enfermedad, en mi infancia[...] (19). Parece que la debilidad nos vuelve a la infancia y nuestros sentidos gozan con todo hallando a cada cosa la novedad y el atractivo que los niños le encuentran. Ninguna mala pasión, ninguna de esas ideas insanas que son el sustento de la sociedad, germina en la cabeza de un convaleciente (21).

En el otro extremo hallaremos asimismo representaciones de lo opuesto. En estas se recriminará ese estado que se hace adulto hasta lo envejecido, hasta lo desgastado y seco (ausente de agua), como aquella, en la que denuncia la limitación de un anciano asensorializado, poco dispuesto a la percepción, sordo a lo poético y sin pulso vital o humano, el cual "no oye los salmos que canta el agua”, pues "Las pasiones han abandonado su corazón” y puede en él "la costumbre cotidiana que lo obliga a cumplir sus deberes maquinales" (31).

Otra de las posibilidades hídricas vinculadas a este espacio de la infancia aparecerá constituida por una presentación de los hechos a través de los filtros de la rememoración, la imaginación o la fantasía. Se ponderan aquí las esferas del espacio privado y del tiempo afectivo, frente a las que por el contrario nos remitirían a un espacio público y a un tiempo que sería respuesta a la racionalidad o al acontecer ajeno: "en el colegio, la lluvia solía venir a embargar mis sentidos" (25) y las olas “cantan en tono mortificante la leyenda de nuestros pesares, retirando la mente a los tiempos lejanos de nuestra infancia[...] o a los menos remotos del romance de nuestra vida" (161). No deja de insistirse en la interacción de fluidos temporales y acuáticos:

Mi pensamiento volaba entonces a mis primeros años; me cubría la cabeza con las frazadas y mientras la lluvia cantaba en voz baja todas las elegías de la desdicha, mi delicia era representarme mi casa, las personas que conocí $\mathrm{y}$ amé primero y mi propia figura correteando sin zapatos [despojamiento de signos asociados a la civilización, desnudez primigenia, contacto directo con el agua] por el patio anegado (25-26).

El segundo grupo de espacios generados por esta experiencia del distanciamiento corresponderían a los de la propia psiquis. El resultado de los 
mismos nos introduce en ese mundo desobjetivizado, nacido de un yo que, aquiescente con el agua - agua vehicular-, tendrá la capacidad, bien de forjar, bien de proyectarse, ofreciéndonos en esa configuración personal de la realidad diferentes registros del sujeto.

De tal propuesta surgen, entre otros, los que se deben a una interiorización o transformación de lo real a través de dicha entidad egotista: "Mi imaginación corría entre tanto por donde se le antojaba[...]. He ahí una superioridad del pensamiento sobre las impresiones reales.[...] yo veo llover cuando quiero" (38-39). Pero también aquellos en los que el agua iba a intervenir como expresión de una naturaleza receptiva a la afectividad, auxiliadora y colaboradora sensible, de corte animista, la cual, en ocasiones, se convierte en la extensión del sujeto, de la experiencia íntima, de los estados de ánimo. Opuesta a ella, a su campo de acción, subyace la hostilidad representada por el territorio de los filisteos y agiotistas, por la civilización urbana: maquinaria social deshumanizada y revulsivo de un natural que no perciben o incluso rehúyen.

Así se integraba por ejemplo la lluvia en la constitución del emisor: "La siento [la lluvia] con cada átomo de mi cuerpo, la anido en mis oídos y la gozo con inefable delicia" (19), de igual modo que en "A bordo", otra de las composiciones pertenecientes a este PrometeoECía, lo hacían las olas, erigiéndose en portavoces de esa profundidad emocional y recóndita del individuo:

Las olas cantan en tono mortificante la leyenda de nuestros pesares, retirando la mente a los lejanos tiempos de la infancia, cuando una madre desvelada mecía nuestra cuna, o a los menos remotos del romance de nuestra vida, cuando la voz temerosa del amor correspondido nos murmuraba sus caricias en nuestros oídos (161).

Asimismo, como dijimos, es humanamente capaz, y capaz de la empatía: "mientras estudiaba medicina, en mi cuarto húmedo y sombrío, la 
lluvia caía mansamente[...] acompañando a bien morir a los que expiraban en las salas" (26).

Tampoco faltan alusiones a esa colisión entre la realidad del sujeto poético, (permeable, desguarnecido) y la del ciudadano burgués (impermeable, guarnecido), a través, nuevamente, de dicho fenómeno meteorológico y de todo lo que este pueda llegar a significar dentro del sistema de representaciones del autor, según se va exponiendo:

Las gentes de esta ciudad han podido verme con mi sombrero grande caminando lentamente por las veredas, mientras otros corren presurosos buscando un abrigo contra la lluvia. Yo prefiero mojarme y salgo a gozar cuando llueve, como los demás hombres cuando hace lo que ellos entienden por buen tiempo[...].

Por mí, bien podía no haber paraguas ni capas de goma, ni impermeables. Me irrito cuando algún tonto llama mal tiempo al lluvioso[...], los viandantes andan de prisa vestidos de fantasía, los carruajes se ponen en movimiento y van dando cabezadas a un lado y otro como quien opina de diferente modo; los carros de los vendedores atraviesan despavoridos las bocacalles[...] (27-28).

Una lluvia pasional, cualitativamente humana, reproducirá además con su ritmo el encuentro amoroso - auténtico pero furtivo- entre dos amantes, hasta confundir su movimiento, su cadencia, sus humores, con los de la joven pareja: "Y la lluvia batiendo su compás comienza de nuevo fuerte, calmada, violenta, bulliciosa, alternativamente, acompañando con sus tonos dulcísimos las vibraciones de dos corazones henchidos de amor y de zozobra" (30). En el otro extremo, se nos muestra por el contrario el momento carnal que tendrá lugar durante el transcurso de una noche de bodas. Se trata de un episodio carente de sentimiento, marcado por la crueldad que permanece oculta tras un formalismo social, en el cual, esa lluvia se identificará solo con uno de los dos protagonistas: no con el "brutal prosaico cuyos botines han atronado al caer sobre el piso de madera (33)", sino con la esposa de "frente virginal" (32), la niña víctima de un enlace convenido que se exhibe visiblemente despojado de humanidad y afecto: 
[...] la desposada suspira, llora y se queja como un tierno pájaro que expira[...]. De repente[...] se oye [sic] los golpes espaciados de las gotas en los postigos de la ventana, como preludios de la lluvia que comienza; lluvia de lágrimas en delicado homenaje a una virginidad sacrificada y doliente, elegía que penetra en el alma de la joven con la melancólica suavidad de un recuerdo lejano... (33).

Otro de los reguladores poéticos de ese espacio psíquico intermediado por lo acuático nos sitúa ante la sucesión de un tiempo moroso, ante la suspensión temporal, como inductores eficientes de la vivencia de lo lírico (tiempo contemplativo, detenido): "Yo habría querido petrificar mis sentidos y que la lluvia continuara eternamente" (23), "Yo solo existía para adormecerme con la elegía de la lluvia y una deliciosa estupidez se apoderaba de mí sin que fueran capaces de sacarme de ella” (25). Opuesto a este discurrir percibiremos el efecto nefasto del que es responsable un tiempo mecanizado, pero sobre todo, acelerado, sin ocasión para la reflexividad o la interiorización de los hechos, que nos involucra en el mero acto de la subsistencia (tiempo activo, precipitado): "los vendedores de todo y los compradores de todo[...] salen, bajan, pululan, se atropellan, se empujan, hablan, gritan, llaman, golpean" (13-14); se trata de ese "Vivir en el bullicio del mundo, allá en las grandes ciudades llenas de intrigas y de conflictos que acortan, disminuyen y destruyen el tiempo[...] hasta dejarlo invisible" (164).

También son fruto de la desojetivización, de esa suerte de distanciamiento con respecto a lo prosaico y ordinario, los paisajes psíquicos obtenidos por una puesta en marcha de las que podrían denominarse percepciones ampliadas. Es la vía hacia cierta realidad sensorializada, sensualizada, y re-tratada en ocasiones por las paletas verbales del impresionismo: "La naturaleza ha puesto la expresión de los inmensos dolores fuera del alcance del lenguaje articulado, entregándosela a la música y a la pintura. Para sentir no basta entender, es necesario oír y ver (61)"; y así oye Wilde "la lluvia que comienza y que ha venido a despertarme tocando con sus dedos de cristal los cristales de mi ventana (75)". Son pródigos a lo largo de todas las com- 
posiciones incluidas en la obra que nos ocupa este tipo de escenarios: "Y los versos salían de mi garganta como cascadas, como huracanes[...] ensordeciendo como los yunques del averno, como las olas, como el trueno, como el viento (7)", o el que con plasticidad y serosidad etológica, temperamental, no dejará de pincelarnos en aquella "Utilidad en la desgracia“, por citar algunos:

[...] cielo gris, lluvia, luz difusa variable, con penumbras, parece enmohecida, pegajosa y aburrida de haber dejado el sol para caer sobre la tierra a través de una atmósfera hipocondriaca y tormentosa[...]. Qué bien sienta un día así cuando uno es desgraciado! (79)

Un tipo diferente de espacios que poéticamente conviven con los expuestos hasta el momento parecen hallar su foco, según anunciábamos, alrededor de esa experiencia centrada en la transformación.

Dentro de ellos, un primer grupo surgirá del extrañamiento, de esa propuesta de Wilde ante el fracaso de aquella realidad que en su época se había establecido como modelo vigente, normal, normalizado. Hablamos de un cierto fallo de solidez en ese patrón - hasta cierto punto limitado, constreñido- de mundo preceptivo, lógico, científico, objetivo o sin fisuras, que finalmente se pone en duda y desmorona al admitirse, más allá de su diseño, determinados accesos válidos para una vivencia incorrecta, incómoda, improductiva, de lo extraño. Dicha anomalía de lo real —en colaboración, por supuesto, con los agentes modificadores y poetizadores del agua- suele aparecer en repetidas ocasiones bajo el dominio de lo sobrenatural, de lo extraordinario, llegando incluso a aproximarse a la categoría estética de lo fantástico, pues entre otros factores, dejarán de ser infranqueables determinadas puertas del orden: se autoriza la ruptura del tiempo lineal, el traspaso de fronteras entre lo animado y lo inanimado, el de las existentes entre el yo y lo otro, o la irrupción - amenazadora e inquietante- del misterio. Esta forma de romper la realidad preceptiva nos sitúa ante dislocaciones como 
las siguientes: "En un momento recorrí veinte siglos y cuatrocientas mil leguas" (38); "No puedo dormir; mi alma se sale de mi cuerpo y se va a la calle semi-oscura y húmeda, donde los faroles de gas parecen jaulas aburridas, que encierran canarios aburridos ardiendo" (77), o "creo notar que mis ventanas pestañean $[. .$.$] es una gruesa nebulosa de agua que se interpone, o alguna nu-$ be más densa vestida de medio luto que arrastra su cola en el espacio" (79).

Un segundo grupo estaría constituido por los espacios del humor. Estos nos conducen de nuevo al cuestionamiento, a la rasgadura y a la desaprobación de aquella realidad convencional, consolidada por los valores utilitarios, materialistas, escasamente humanos, y en definitiva, tan poco prometeicos, que Wilde observaba voraces en su sociedad.

Entre las muchas posibilidades ilustrativas de esta maniobra transformadora, destacaríamos, por ejemplo, la ocultación cómica con la que nuestro autor enmascaraba su sentimiento nostálgico hacia aquella civilización ideal aludida, digna de Prometeo, que lamentablemente no lograría hallar entre sus contemporáneos. Ante tal ausencia, la de esa comunidad definida por valores constitutivos de una auténtica Belleza (Belleza inconmensurable, exponente de riquezas espirituales, pero considerada inútil por no resultar rentable), se genera un sentimiento de frustración, pues el asentamiento, que por el contrario se constata, será el de una belleza falsa, tan solo aparente (belleza mensurable, signo de una posesión-colección de riquezas materiales, belleza útil y rentable). Hay, como consecuencia, y como en tantas ocasiones registradas en los diferentes apartados que hemos ido abordando, un ensalzamiento del entorno rural, del goce estético inducido en el ser humano por los estímulos de la naturaleza (ambos, territorios propios del agua en cuanto elemento natural que es), libres y distanciados de la convención social, auténticos promotores de un reencuentro del individuo con su propia esencia. Como contraposición a este sentimiento de loa que Eduardo Wilde nos daba a conocer, no se escatiman muestras de lo opuesto, 
de su desaprobación estética (a la par que ética) con respecto al universo del agiotista, del burgués, del filisteo. De este último se declaraba bastión aquel espacio urbano criticado por él, en el cual no faltaban signos de poder, como los traducidos en el afán de conquista y exhibición al por mayor de bienes materiales, indicativos de la falta de gusto o de criterio, pero también de una posición social encumbrada. Los espacios de interiores, asfixiantes por la acumulación del mobiliario, por la congestión del material precioso y por un muestrario sin sentido del objeto raro de belleza, eran algunos de los objetivos de la mordacidad de Wilde contra ese exceso vano de civilización. Bajo esta óptica lo percibíamos en su "Vida moderna":

[...] soy el hombre más feliz de la tierra; me sobra casa, me sobra ropa, me sobra comida y me sobra tiempo; no tengo reloj [...]. ¿Sabes por qué he venido? Por huir de mi casa donde no podía dar un paso sin romperme la crisma contra algún objeto de arte. La sala parecía un bazar[...]; la luz [agente natural] no entraba en las piezas por causa de las cortinas [agente artificial];[...] el aire [agente natural] no circulaba por culpa de los biombos, de las estatuas, de los jarrones [agentes artificiales] y de la grandísima madre que los dio a luz[...] (103). Lo primero que se me ocurre al entrar en un salón moderno es pensar en un buen remate o en un terremoto que simplifique la vida[...] Tengo intención de pasar aquí una temporada, y estaría del todo contento si no fuera la espantosa expectativa de volver a mi bazar. [...] Hasta he pensado alguna vez en fingirme loco y arrojar a la calle por la ventana los bustos de los hombres más célebres, los cuadros, las macetas, las arañas y los espejos (106-107).

De igual manera se construyen estos territorios del humor a través de la doble representación del ser humano que el autor nos brinda. Antitéticamente al retrato honesto, admirable, profundo, espiritual y sensible, distintivo de la naturaleza del hombre prometeico - hombre ideal-, nos ofrecerá esa caricatura o presentación grotesca que a sus ojos merecía el individuo pragmático, desnaturalizado, superficial y grosero, modelado por la falacia de la costumbre social. Así sucedía, por ejemplo, en escenas como aquellas que daban cuerpo a los sentimientos de duelo o dolor. En ellas, según advertíamos en puntos anteriores, la lluvia, la naturaleza en general, acompañaban al sujeto, convirtiéndose en receptores o en proyectores 
de las verdaderas aflicciones. No ocurriría así en las protagonizadas por el ciudadano hecho al aparato social, sumamente propenso a trivializar ese tipo de acontecimientos punzantes hasta reducirlos a un mero trámite, a un formalismo, o a esa clase de oportunidad idónea para el comercio. En esta realidad, humorísticamente transformada y volteada, los seres se mecanizan como piezas de un engranaje, al tiempo que los objetos - útiles de la mordacidad y del sarcasmo de Wilde- asumen rasgos de esa humanidad añorada por él:

Y qué bueno es vivir en un pueblo donde hay carruajes de todas las clases y de todos los precios;[...] poder llevar un buen acompañamiento y que hasta los caballos y los vehículos se vistan de luto[...] ¡Cómo retrata esto los sentimientos humanos![...], y hasta las teteras con capuchón de duelo son la expresión más seria del pesar por la pérdida[...], iqué té tan amargo hacen cuando están de luto![...] Y los cocheros[...] que han aprendido a afligirse por el fallecimiento de todos los desconocidos, o por la tarea monótona de transportarlos[...] ¡qué pesar insólito manifiestan en sus sombreros abollados[...] mientras metodizan su marcha, gestionando la última cuenta de su patrón[...] junto con las coronas de siempre-vivas, marcadas por una calumnia de terciopelo negro que dice: “ijeterno recuerdo!!” (67-68).

En definitiva, los atributos y atribuciones de estos espacios, tanto físicos como conceptuales, pertenecientes a las diferentes composiciones que forman parte de PrometeoECía, han servido para materializar y entender el contraste entre la realidad que desea y la realidad que desdeña quien, en su visión, nos daba muestras de grandeza humana pero también lírica, hasta dejarnos transitar por cada una de ellas. Bajo la diversidad de manifestaciones, el rastreo topopético de su escritura no solo nos permitió el hallazgo de constantes temáticas y de elementos recurrentes representativos de las mismas, que fueron clave para la sistematización y posterior reconstrucción -plástica e ideológica a un tiempo- de los universos del autor (tanto el subjetivo de su yo lírico y acuático, como el de aquella civilización ideal supeditada a un yo prometeico), sino para entender que los valores contenidos en ambos no tenían lugar, a su modo de ver, en la sociedad que le fue 
contemporánea: apoyados o representados por los registros múltiples y multiformes del agua, así como por esa entraña simbólica, más que expresiva, del fuego de Prometeo, entroncan con la espiritualidad, con lo trascendente, con la sensibilidad, con lo subjetivo, lo irracional y la Belleza (principios que ni interesan ni se entienden en el ámbito de una realidad moderna, cuyo progreso se debe a un orden predominantemente material, intrascendente, objetivo, racional y utilitario).

Aprovechando pues la capacidad poética, conductora, y, en algunas ocasiones, ontológica, que Eduardo Wilde confería a lo acuático, sirva como cierre una última participación en este momento de lluvia, en el que, bien como sujetos también líricos, bien como sujetos de su civilización moderna, elijamos — deseantes con él- cantar, o por el contrario — sin él- contar el agua:

En otra escena, en medio de la ciudad bulliciosa, los diarios de la mañana y de la tarde instalan en sus columnas de telegramas, la biografía y el itinerario del último aguacero[...], los pluviómetros marcan insolentemente la cantidad de agua caída en cada metro cuadrado, con la indiferencia científica de los datos físicos y la poética, la sublime, la encantadora lluvia, pasando por la Bolsa de comercio, experimenta la degradante y final transformación de las delicias humanas, convirtiéndose en dato estadístico y objeto de especulación (33-34).

\section{BIBLIOGRAFÍA}

Aínsa, Fernando (2006), Del topos al logos. Propuestas de geopoética, Madrid: Iberoamericana.

Andrade, Olegario Víctor (1887), Obras poéticas, Buenos Aires: Jacobo Peuser.

Bachelard, Gaston (1965), La poética del espacio, México: Fondo de Cultura Económica.

Bachelard, Gaston (2002), El agua y los sueños, Madrid: Fondo de Cultura Económica.

Calinescu, Matei (1991), Cinco caras de la modernidad. Modernismo, vanguardia, decadencia, Kitsch, posmodernismo, Madrid: Tecnos.

García Mérou, Martín (1973), Recuerdos literarios, prólogo y notas de Julia Elena Sagaseta, Buenos Aires: Editorial Universitaria.

Ghiano, Juan Carlos (1953), Constantes de la literatura argentina, Buenos Aires: Editorial Raigal.

Gullón, Ricardo (1984), La novela lírica, Madrid: Cátedra.

Jitrik, Noé (1968), El 80 y su mundo, Buenos Aires: Editorial Jorge Álvarez.

Lugones, Leopoldo (1910), Prometeo (un proscripto del sol), Buenos Aires: Ediciones de los Talleres Otero y Co.

Malosetti Costa, Laura (2003), Los primeros modernos. Arte y sociedad en Buenos Aires a fines del siglo XIX, Buenos Aires: Fondo de Cultura Económica. 
Marún, Gioconda (1993), El modernismo argentino incógnito en La Ondina del Plata y Revista literaria (1875-1880), Santafé de Bogotá: Instituto Caro y Cuervo.

MÉndez, Evar (1915), prólogo, en Olegario V. Andrade, Obras poéticas, Buenos Aires: La Cultura Argentina.

Prieto, Martín (2006), Breve historia de la literatura argentina, Buenos Aires: Taurus.

Romero, José Luis (1976), Latinoamérica: las ciudades y las ideas, México: Siglo XXI.

VIÑAS, David (1995), Literatura argentina y política. De los jacobinos porteños a la bohemia anarquista, volumen I, Buenos Aires: Editorial Sudamericana.

Wilde, Eduardo (1878), Tiempo perdido, segunda parte: trabajos literarios, Buenos Aires: Sociedad Anónima de Tip., Lit. y Fund. de Tipos a Vapor.

Wilde, Eduardo (1899), Prometeo \& Cía., Buenos Aires: Jacobo Peuser.

Wilde, Eduardo (1914), Aguas abajo, Buenos Aires: Jacobo Peuser.

Recibido: agosto de 2020

Aceptado: noviembre de 2020 